\title{
STUDYING THE EFFECT OF DIFFERENT VARIABLES ON THE FORMULATION OF MUCOADHESIVE BUCCAL PATCHES OF CAPTOPRIL
}

\author{
ZAINAB AHMED SADEQ, NAWAL AYASH RAJAB \\ Department of Pharmaceutics, College of Pharmacy-University of Baghdad, Baghdad-Iraq \\ Email: wahaj_1977@yahoo.com
}

Received: 26 Nov 2016, Revised and Accepted: 02 Mar 2017

\section{ABSTRACT}

Objective: The objective of this research was to formulate the captopril as mucoadhesive buccal films for hypertension treatment and studying the effect of different variables on the physical and mechanical behavior of the prepared films.

Methods: The bucco-adhesive patches were prepared using hydroxyl propyl methyl cellulose K4 (HPMC) as film forming a polymer with secondary polymer included carbopol 934 and eudragit RL100. The patches were prepared by a solvent casting method and evaluated for the weight variation, surface $\mathrm{pH}$, mechanical properties, content, uniformity, ex-vivo mucoadhesive strength, ex-vivo permeation study and drug release study.

Results: Formula F5 containing HPMC as primary polymer with carbopol 934 as secondary polymer was chosen to be the best formulation for the following parameters: surface pH6.44, tensile strength (16.06), percentage elongation at break (34.14), swelling index(18.85), mucoadhesive strength $(26.2 \mathrm{gm})$ and the folding endurance was $>300$ with an in vitro drug release about $94.73 \%$ during $6 \mathrm{~h}$.

Fourier transforms infrared spectroscopy (FT-IR) and differential scanning calorimetric studies (DSC) showed no interaction between the drug and polymers.

Conclusion: It can be concluded that oral mucoadhesive buccal film of captopril, an antihypertensive agent can be prepared utilizing HPMC as a film forming a polymer with carbopol as a secondary polymer which extended the drug release through the buccal mucosa for $6 \mathrm{~h}$.

Keywords: Captopril, Buccal patches, Hydroxyl propyl methyl cellulose and carbopol

(C) 2016 The Authors. Published by Innovare Academic Sciences Pvt Ltd. This is an open access article under the CC BY license (http://creativecommons.org/licenses/by/4.0/) DOI: http://dx.doi.org/10.22159/ijap.2017v9i2.16345

\section{INTRODUCTION}

The sites of oral mucosa are dissimilar from each other in the anatomical construction, drug permeation and their capability to hold a delivery dosage form for a definite period of time [1]. Though the sublingual area has a high absorption ability, good blood supply and high bioavailability, but it is unsuitable for the sustained drug administration due to the sublingual area lack immobile smooth muscle and washed by adequate volume of saliva make it suitable for a drug with short time management and frequent use $[2,3]$. Drug delivery through the buccal mucosa is an innovative method for local and systemic management since the buccal mucosa is permeable with high blood supply and permits long-time retention of the dosage form [4]. Captopril is an antihypertensive drug used for the management of hypertension and heart failure through reduction of angiotensin II and an increase of bradykinin production [5]. Also, it has a renoprotective effect in the diabetic patient [6]. Furthermore, approximately 60$75 \%$ of captopril is absorbed through the gastrointestinal tract, and the peak plasma concentrations are obtained through $1 \mathrm{~h} \mathrm{[7].}$ It has two dissociations constant pka1 (3.7) and pka2 (9.8), the half-life about 1-2 h [8]. Hence captopril is a suitable candidate for the buccal drug administration. The objective of this study prepared captopril as a mucoadhesive buccal film for hypertension treatment in order to increase bioavailability, reduce dosing frequency and improve patient compliance via solvent casting method and studying the effect of different variables on the physical and mechanical properties of the prepared films.

\section{MATERIALS AND METHODS}

\section{Materials}

Captopril obtained from Awamedica, Iraqi company as a gift sample, (HPMC), carbopol and polyvinyl alcohol (PVA) were obtained from fine Indian chemicals. Eudragit was obtained from Rohm, GmbH, Weiterstdt, Germany, England. Propylene glycol (PG) was obtained from Evans Medical Ltd, Liverpool. All other reagents and chemicals used were of analytical grade.

\section{Instruments, equipment and apparatus}

Different instruments, apparatus and equipment, have been used in this study: Digital venire caliper obtained from Shanghai (China), $\mathrm{pH}$ meter obtained from radiometer (Denmark), UV spectrophotometers obtained from emclab gmbh (Germany), Dissolution type (2) apparatus obtained from Coply scientific (UK), FT-IR spectrophotometer obtained from Shimadzu (Japan), differential scanning calorimetry obtained from Shimadzu (Japan).

\section{Formulation of captopril mucoadhesive buccal film}

Eight formulations(F1-F8) were prepared (table 1) by a solvent casting method using the different percentage of polymer and each film with a surface area approximately four $\mathrm{cm}^{2}$ are loaded with $12.5 \mathrm{mg}$ captopril. The PVA solution was prepared by dissolving the polymer in hot water at $\left(60-100^{\circ} \mathrm{C}\right)$ then the solution was left to cool [9]. While (HPMC) solution was prepared by heating $20-30 \%$ of distilled water volume with stirring to $\left(80-90^{\circ} \mathrm{C}\right)$ then HPMC was added. After that, the final volume was completed with cold water under stirring [10].

In all the formulas, the polymers were dissolved in a proper solvent with stirring under magnetic stirrer. Then PG as a plasticizer $(30 \%$ of polymer weight) was added. Finally captopril powder $12.5 \mathrm{mg}$ was added to the polymer solution. The prepared solution was left overnight to get rid of the air bubbles.

Then these solutions were poured into aluminium foil (to be used as a backing layer) in a glass moulid of diameter $9 \mathrm{~cm}$ and left to dry in a hot air oven adjusted at $50{ }^{\circ} \mathrm{C}$ until flexible patches were obtained. The dried patches were divided into $2 \times 2 \mathrm{~cm}^{2}$ diameter and then used for this study.

\section{Evaluation of captopril mucoadhesive buccal patch}

\section{Weight variation}

Three randomly chosen patches were selected and weighed everyone alone using a digital balance then the mean value for each formulation was measured [11]. 
Table 1: Composition of captopril mucoadhesive buccal patch

\begin{tabular}{|c|c|c|c|c|c|c|c|c|}
\hline \multirow[t]{2}{*}{ Ingredient (mg) } & \multicolumn{8}{|c|}{ Formula code } \\
\hline & F1 & F2 & F3 & F4 & F5 & F6 & F7 & F8 \\
\hline Captopril & 12.5 & 12.5 & 12.5 & 12.5 & 12.5 & 12.5 & 12.5 & 12.5 \\
\hline PVA & 93.75 & 93.75 & 93.75 & & & & & \\
\hline HPMC & & & & 93.75 & 84.38 & 75 & 84.38 & 75 \\
\hline Carbopol934 & & & & & 93.75 & 18.75 & & \\
\hline Eudragit RL100 & & & & & & & 9.37 & 18.75 \\
\hline PG & 18.75 & 28.125 & 37.5 & 28.125 & 28.125 & 28.125 & 28.125 & 28.125 \\
\hline
\end{tabular}

\section{Thickness}

Three patches randomly are chosen from each formulation and after that, the thickness was measured at five points using a digital venire caliper, then the average value was taken [12].

\section{Folding endurance}

This test gives the idea about elasticity and flexibility of patches. It was determined manually by repetitively collapsing single patch at the same point until broken. The number of times of foldable at which the patch is not broken to indicate the value of folding endurance [13].

\section{Surface pH}

In this test, film was allowed in contact with five $\mathrm{ml}$ of distilled water for $60 \mathrm{~min}$ at room temperature and then the $\mathrm{pH}$ measured by using $\mathrm{pH}$ meter, this done in triplicate and take the mean value [14].

\section{Content uniformity}

This test was measured by dissolving the patch $(2 \times 2) \mathrm{cm}^{2}$ in $100 \mathrm{ml}$ phosphate buffer pH 6.8 under magnetic stirrer for $60 \mathrm{~min}$, then the end result solution filtered, diluted with phosphate buffer and determined drug content by UV spectrophotometer at wavelength $206 \mathrm{~nm}$ in triplicate [15].

\section{Tensile strength and percentage of elongation}

Tensile strength (TS) is the maximum stress applied to a point at which the film breaks. Elongation is defined as a measure of the capacity of a patch to deform prior to failure. Tensile strength and percent elongation (\% EB) of the patches were determined on tensile strength testing apparatus. Rectangular patch strips of $5 \times 2$ $\mathrm{cm}^{2}$ were fixed between the jaws of the instrument. The load on the strip was gradually increased to a maximum at a speed of 50 $\mathrm{mm} / \mathrm{min}$. and the change in the length of the strips that occurred with increasing stress was measured. TS and (\%EB) of three patches of each batch were measured [16].

\section{Swelling index}

For determining the swelling index, the film $(2 \times 2) \mathrm{cm}^{2}$ was weighed on a pre-weighted microscope slide $\left(\mathrm{W}_{0}\right)$ and kept in a Petri dish containing $50 \mathrm{ml}$ buffer solution. For one hour and at a regular period interval, the microscope slide was removed from Petri dish and reweigh again (Wt.). The mean of three determinations was recorded [17]. Then the swelling index was measured by using the following equation:

$$
\text { Swelling index }=\left(\mathrm{Wt}-\mathrm{W}_{0}\right) / \mathrm{W}_{0} \times 100(1)
$$

Where $W_{0}$ is the weight of the patch before dipping into a phosphate buffer solution $\mathrm{pH} 6.8, \mathrm{Wt}$. is the weight of the patch after dipping into a phosphate buffer solution $\mathrm{pH} 6.8$.

\section{Ex-vivo mucoadhesive strength}

A modified physical balance (locally assembled) was utilised for measuring the mucoadhesive strength. The fresh chicken pouch was used as a model (taken from the slaughter house and must use during 120 min since slaughter) [18]. The pouch was washed with phosphate buffer solution, pH 6.8 and attached at the bottom of the Petri dish by the help of cyanoacrylate glue; a glass stopper is hanged by threads at equal space from the left-hand pan. To the lower end of the glass stopper, the film was attached by cyanoacrylate gum just above the pouch membrane. The right pan holds an empty beaker; the two pans must balance by the addition of a proper weight, after that a five-gram weight is removed from the right pan, in order to make the film in contact with pouch membrane. The balance was leaved in this situation for five minutes. Then distilled water was slowly added to the empty beaker until the film separate from the chicken pouch. The weight required to separate the film from the chicken pouch represents the measurement of mucoadhesive strength $[19,20]$.

The forces of adhesion and bond strength were calculated using following equations:

Force of adhesion $(\mathrm{N})=$ Mucoadhesion strength $/ 1000 \times 9.81(2)$

Bond strength $\left(\mathrm{N} / \mathrm{M}^{2}\right)=$ Force of adhesion $(\mathrm{N}) /$ Surface area $\left(\mathrm{M}^{2}\right)(3)$

\section{In vitro release study}

All the prepared captopril buccal patches were measured using a dissolution apparatus, adjusted at $37{ }^{\circ} \mathrm{C}$, rotate at $50 \mathrm{rpm}$ and the dissolution jar filled with a $500 \mathrm{ml}$ phosphate buffer solution $\mathrm{pH} 6.8$ [21]. In order to produce a unidirectional drug release, the patch $(2 \times 2) \mathrm{cm}^{2}$ was placed upon glass slide by the help of cyanoacrylate glue, then the slide immersed in the dissolution apparatus jar. Aliquots of five ml sample were taken from the jar at regular time period $(15,30,60,120,180,240,300$, and 360) min and replaced with equal volume of buffer solution since the drug is soluble. The sample suitably diluted and analyzed by UV spectrophotometers at $206 \mathrm{~nm}$ wavelength, then the dissolution profile of captopril is constructed by plotting the percent of accumulative drug release against time. The mean of three determinations was recorded [22].

\section{Drug polymer compatibility study}

\section{Fourier transform infrared spectroscopy (FT-IR)}

Fourier transforms infrared spectroscopy was determined to find any physical or chemical interaction between the drug and other material used in the dosage form. FT-IR spectrum was performed for the pure captopril powder and the selected formula. Samples were mixed with potassium bromide and pressed to form a disc; then this prepared disc was investigated using FT-IR spectroscopy in the range 4000-40 $\mathrm{cm}^{-1}[23]$.

\section{Differential scanning calorimetric studies (DSC)}

Differential scanning calorimeter (DSC) was used to determine the loss or gained of heat, produced from physical or chemical change inside the sample as a function of heat. The DSC scans were employed for pure captopril powder, a physical mixture of polymer and the drug in a ratio $(1: 1)$ and for selected captopril mucoadhesive buccal patch. The test was carried by using a Shimadzu DSC apparatus with temperature range 50-300 and in a rate $10 / \mathrm{min}$ [24].

\section{Statistical analysis}

The results of the experimental work were demonstrated as a mean of triplicate models $( \pm S D)$ were examined in relation to the one-way analysis of variance (ANOVA). The differences were considered statistically significant when $(\mathrm{P} \leq 0.05)$ and non-significant at a level of $(p>0.05)$.

\section{RESULTS AND DISCUSSION}

\section{Physical evolution}

The average weights for all prepared formulations were uniform and ranged (149.04-174.18 mg), All the captopril buccal patch showed a 
satisfactory thickness $(0.225-0.330 \mathrm{~mm})$ and folding endurance more than 300 , the surface $\mathrm{pH}$ value (6.38-6.88), when compared to that $\mathrm{pH}$ of oral mucosa indicating that it doesn't cause an irritation to the buccal mucosa.

\section{Content uniformly}

The formulated captopril buccal patch showed the acceptable quantity of medicament ranged from (93.03-101.01\%). This result met the suitable extend of content uniformly labeled in BP, which is rung from $85 \%$ to $115 \%$. According to that, captopril was spread consistently throughout the four $\mathrm{cm} 2$ constant area of the buccal patches.

\section{Effect of plasticizer concentration}

The result was shown that changing PG concentration $(18.75 \mathrm{mg}$ for F1, 28.125 $\mathrm{mg}$ for F2 and $37.5 \mathrm{mg}$ for F3) which represent (20, 30, and $40 \%$ ) of total polymer weight affect both (TS) and (\%EB). Increasing plasticizer concentration caused a significant decrease $(\mathrm{P}<0.05)$ in TS and significant increase $(\mathrm{P}<0.05)$ in \%EB, this is due that as the concentration of plasticizer increased this lead to loosen the polymer molecule network and decrease the molecule movement within the polymer [25].

So that optimization of plasticizer concentration was achieved by selecting $(28.125 \mathrm{mg}$ ) of $\mathrm{PG}$, which is equal to $(30 \%$ of total polymer weight) that provided both acceptable TS and \%EB. Additionally, there is non-significant $(\mathrm{P}>0.05)$ increased in swelling index as $\mathrm{PG}$ concentration increased (F1, F2, F3) as in fig. (1), this it because of the hygroscopic nature of $\mathrm{PG}$, which leads to a reduction in force between the polymer molecules and increasing moisture content [26].

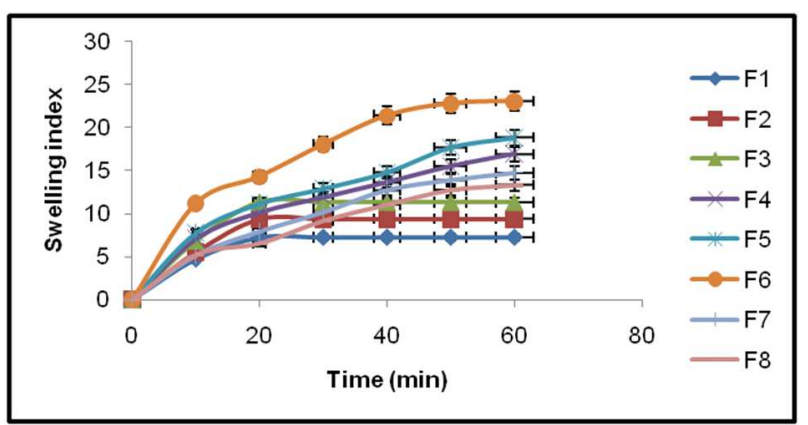

Fig. 1: Swelling index of the prepared captopril mucoadhesive buccal patches (Results are expressed as mean, $n=3$ )

\section{Mucoadhesive characteristics}

There was a significant increase $(\mathrm{P}<0.05)$ in mucoadhesive and bond strength as PG concentration increased because the addition of plasticizer agents reduced the internal stress of the patch by decreasing the glass transition temperature of the polymer and thus increasing mucoadhesion forces [27].
While for in vitro drug release mechanism, as the PG concentration increase, there is a significant increase $(\mathrm{P}<0.5)$ in the amount of captopril released from the film fig. (2), this is because the higher concentration of $\mathrm{PG}$ in the film, the larger number of plasticizer molecules found to produce polymer chain relaxation and subsequent increasing captopril release from the patch [28].

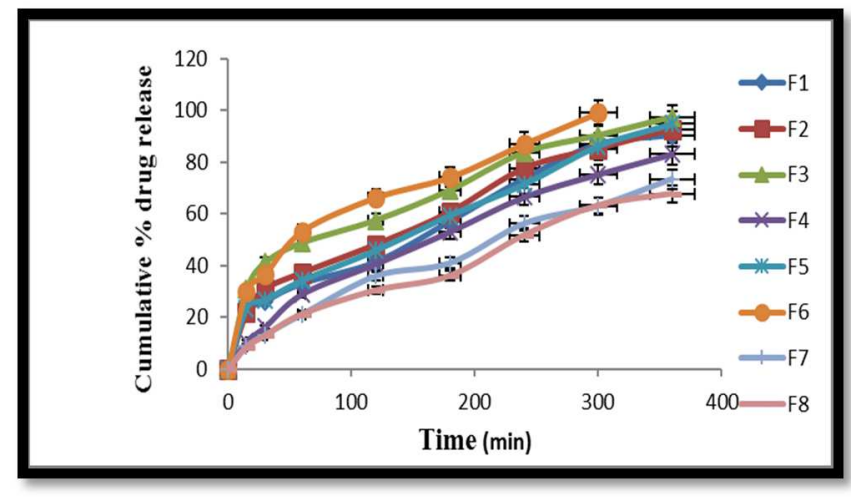

Fig. 2: Dissolution behavior of captopril mucoadhesive buccal patches (Results are expressed as mean, $n=3$ )

\section{Effect of type of film forming polymer}

Results showed that films containing PVA (F2) significantly higher TS $(\mathrm{P}<0.05)$ and $(\% \mathrm{~EB})$ than F4 (containing HPMC) table (2). This is because PVA polymer contains a larger number of chains of molecules and between these chains, there is a homopolar bond, these homopolar bonds either strong or weak according to the polymer type. So that the force required for homopolar bond breakdown and patch rupturing will differ [29].

Swelling index, it was seen that formulas containing PVA (F2) showed significant decrease $(\mathrm{P}<0.05)$ in swelling index than formula containing HPMC (F4) this is because, there is averring in polymer network resistance toward water molecule penetration, same observations seen in the mucoadhesion patch of salbutamol sulphate [30].

Concerning the mucoadhesive characteristics in table (3), it was seen that there is a significant increase $(\mathrm{P}<0.05)$ in mucoadhesive and bond strengths for formula containing HPMC than those containing PVA, this is due to HPMC hydrate rapidly producing maximum swelling at short time, which facilitated polymer chain's interpenetration with mucus membrane, additionally HPMC having higher molecular weight and viscosity than PVA, and contain both carboxyl and hydroxyl group necessary for mucoadhesive. Furthermore, drug release from F4 (483.11\%) at $6 \mathrm{~h}$ slower than from F2(92.57\%), this is explained by HPMC has been an extensive swelling character, which led to produce a thick gel barrier for drug diffusion [31].

Table 2: Tensile strength and percent of elongation of captopril mucoadhesive buccal patches

\begin{tabular}{lll}
\hline Formula no. & TS (MPa)* & \%EB* \\
\hline F1 & $56.32 \pm 1.23$ & $204.12 \pm 11.23$ \\
F2 & $52.20 \pm 0.89$ & $245.40 \pm 9.17$ \\
F3 & $33.01 \pm 1.02$ & $493.25 \pm 14.34$ \\
F4 & $19.50 \pm 0.54$ & $24.06 \pm 1.12$ \\
F5 & $16.06 \pm 0.87$ & $34.14 \pm 0.94$ \\
F6 & $10.15 \pm 0.43$ & $26.80 \pm 0.86$ \\
F7 & $21.15 \pm 0.27$ & $29.06 \pm 0.55$ \\
F8 & $29.90 \pm 0.78$ & $23.13 \pm 0.1 .28$ \\
\hline
\end{tabular}

*SD standard deviation from mean. $\mathrm{n}=3$ 
Table 3: Mucoadhesive characteristic of captopril mucoadhesive buccal patches

\begin{tabular}{llll}
\hline Formula no. & Mucoadhesive strength* (g) & Force of adhesion (N) & Bond strength (Nm-2) \\
\hline F1 & $5.42 \pm 0.20$ & 0.053 & 132.79 \\
F2 & $6.55 \pm 0.03$ & 0.053 & 132.79 \\
F3 & $7.80 \pm 0.111$ & 0.076 & 191.1 \\
F4 & $21.8 \pm 0.511$ & 0.213 & 543.1 \\
F5 & $26.2 \pm 0.256$ & 0.256 & 641.9 \\
F6 & $30.11 \pm 0.228$ & 0.295 & 737.69 \\
F7 & $19.12 \pm 0.505$ & 0.187 & 468.44 \\
F8 & $16.28 \pm 0.107$ & 0.159 & 398.86 \\
\hline
\end{tabular}

*SD standard deviation from mean. $\mathrm{n}=3$

\section{Effect of polymeric blend ratio}

The addition of carbopol 934 in different ratios for the formulas F5 and F6 results in a significantly decreased in TS $(\mathrm{P}<0.05)$ and increased in \%EB as the amount of carbopol increased to produce a flexible and soft patch, a similar finding was observed in designing a buccal patch of salbutamol sulphate [32].

While, addition of eudragit RL 100 to HPMC in different ratios (F7F8) result in a significant increase in TS $(\mathrm{P}<0.05)$ and decrease in $\% \mathrm{~EB}$, this is because of eudragit produces strong cross-linking which leads to increase in the strength bonds of the polymer chains, similar observation was found in development buccal patch of indomethacin [33].

Concerning the swelling index (fig. 1), the addition of carbopol in a different ratio with HPMC (F5, F6) led to significant increase in the swelling index $(\mathrm{P}<0.05)$, this is because of its water solubility allows it to dissolve rapidly to produce high porosity. While using eudragit RL100 as a secondary polymer with different concentrations results in a significant decrease $(\mathrm{P}<0.05)$ in the swelling index as the eudragit concentration increase, this is because of its hydrophobic character and limited swelling ability. While incorporation of carbopol into HPMC (F5, F6) result in a significant increase $(\mathrm{P}<0.05)$ in the mucoadhesive and bond strengths, this is because that carbopol is polyacrylic acid containing both carboxyl and hydroxyl group, which permits the attractive polymer interaction with mucin layers.
While incorporated eudragit with HPMC (F7, F8) results in a significant decrease in the mucoadhesive and bond strength $(\mathrm{P}<0.05)$ as the concentration of the eudragit increase, this is because of absent from a proton donating carboxyl group in eudragit, which permit a formation of a weak hydrogen bonding with mucus membrane. For drug release, in polymer blend containing carbopol (F5, F6), there is a significant increase in drug release $(\mathrm{P}<0.05)$ as the concentration of carbopol increase fig. (2), this is because of the carbopol ionization at $\mathrm{pH} 6.8$ environment, which is higher than its $\mathrm{pKa}$, so that its ionization creates a negative charge on the polymer backbone. The Same charge of polymer and mucin (negative charge) lead to repulsion, increase water uptake and drug diffusion from the matrix [34].

HPMC combination with eudragit (F7, F8), there was a significant decrease $(\mathrm{P}<0.05)$ in drug release as the ratio of eudragit increased because of hydrophobic nature of eudragit and reduced swelling behavior lead to decrease a drug release from a polymer matrix.

\section{Drug polymer compatibility study}

Fourier transform infrared spectroscopy (FT-IR)

The principal peaks of pure captopril and the selected formula F4 were shown in the table (4). The resulted values show that the peaks don't shift significantly in the FT-IR spectra of the selected formula F5 in comparison with the pure captopril as seen in fig. 3 and 4, respectively, and indicating the compatibility of captopril with the additives used.

Table 4: FT-IR absorption bands of captopril and the prepared patch F5

\begin{tabular}{lll}
\hline Characteristic groups & Pure drug [35] & Selected formula(F5) \\
\hline S-H stretching & 2567 & 2565 \\
C=O(in COOH) & 1743 & 1702 \\
C=O (in amide) & 1587 & 1583 \\
C-N stretching & 1227 & 1375 \\
O-H stretching & 3369 & 3352 \\
CH3 bending & 1471 & 1448 \\
CH3 symmetric stretching & 2877 & 2936 \\
CH3 Asymmetric stretching & 2980 & 2976 \\
\hline
\end{tabular}

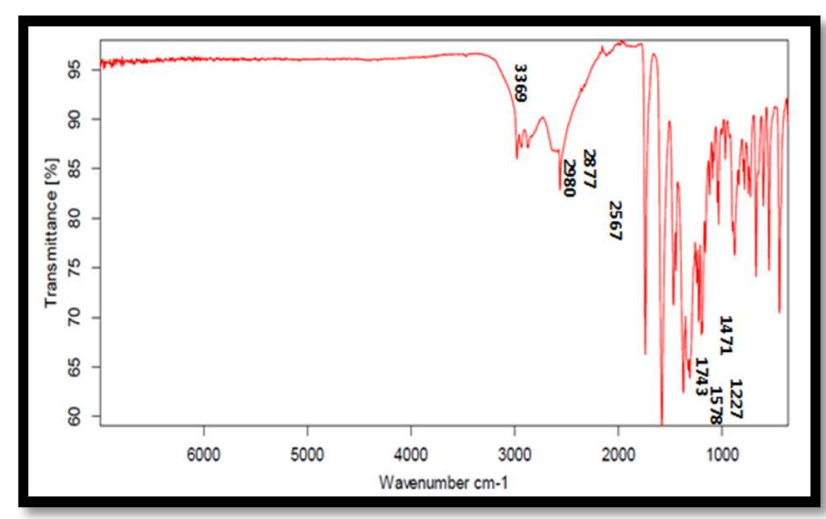

Fig. 3: FT-IR spectrum of pure captopril

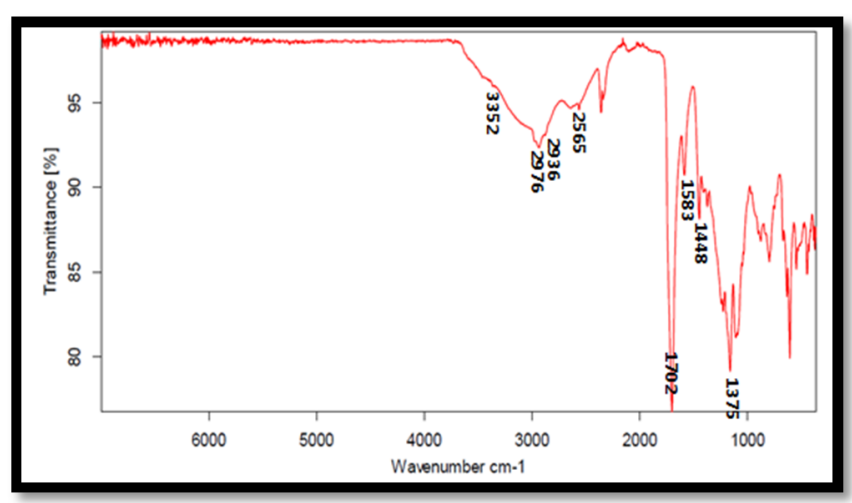

Fig. 4: FT-IR spectrum of the selected formula F5 of captopril mucoadhesive buccal patch 


\section{Differential scanning calorimetric studies}

Captopril peak was clear in DSC thermogram at $111.53^{\circ} \mathrm{C}$ around its melting point fig. (5), which indicate that captopril used in its pure crystalline state as compared with reference [36]. The DSC technique was used to give an idea about the thermal stability of the drug and additives. The DSC of the physical mixture of captopril, carbopol and HPMC give an endothermic peak at $109.43{ }^{\circ} \mathrm{C}$ fig. (6), which indicates there is no interaction between the drug and polymers used, while DSC thermogram of captopril buccal patch shows a complete disappearance of captopril endothermic peak fig. (7), proposing that the captopril was uniformly dispersed in the polymer matrices.

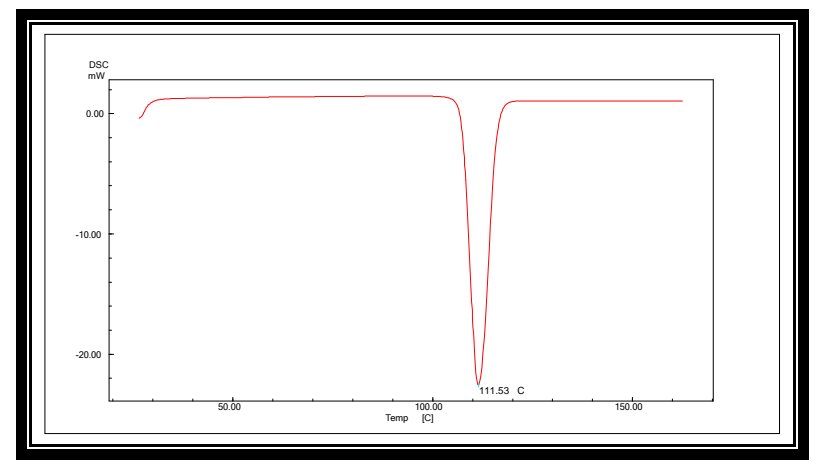

Fig. 5: DSC of pure captopril

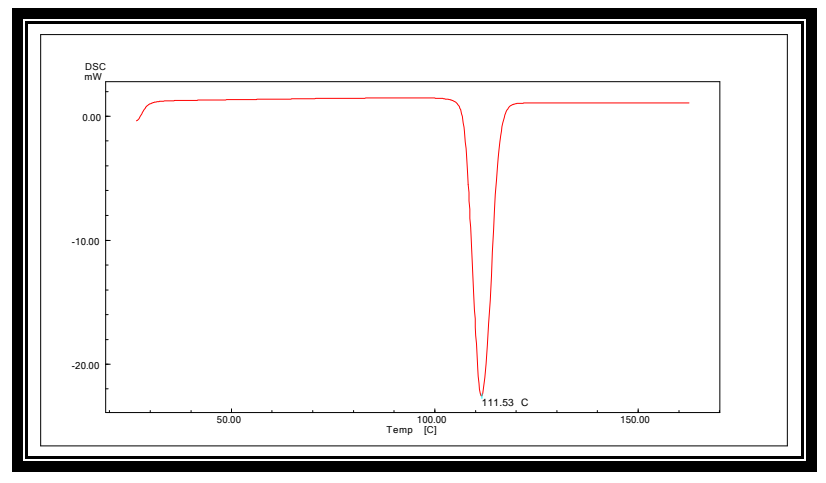

Fig. 6: DSC of the physical mixture of captopril, carbopol, and HPMC

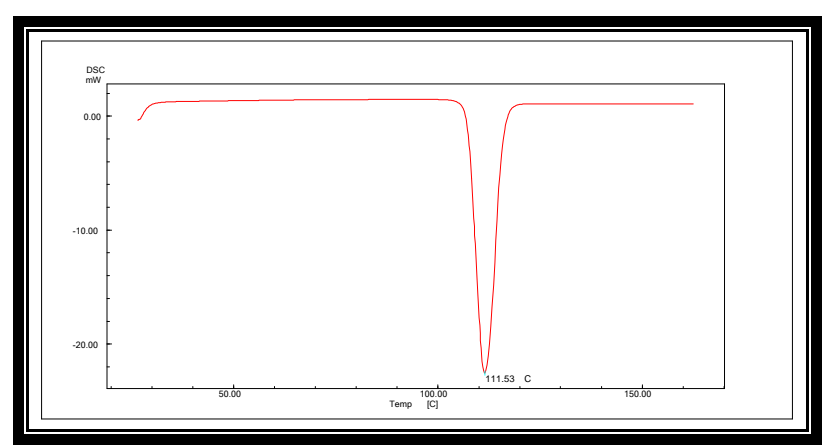

Fig. 7: DSC of the selected formula F5

\section{CONCLUSION}

It can be concluded that formulation F5 using a combination of two mucoadhesive polymers HPMC and carbopol could be used to release captopril in buccal cavity for an extended period of time without the risk of mucosal irritation for hypertension treatment. This will enhance the patient compliance throughout reduction of dosing administration.

\section{ACKNOWLEDGMENT}

I'm very grateful to A. Lecturer Zena M. Qaragholi from the department of Pharmacognosy and medicinal plants/college of pharmacy/University of Baghdad for the revision and language editing.

\section{CONFLICTS OF INTERESTS}

\section{Declare none}

\section{REFERENCES}

1. Mishra S, Kumar G, Kothiyal P. A review on recent approaches in buccal patches. J Pharma Innov 2012;1:78-86.

2. Sangeetha S, Venkatesh DN, Krishan PN, Saraswathi R. Mucosa as a route for systemic drug delivery. Res J Pharm Bio Chem Sci 2010;1:178-87.

3. Shojaei AH. Buccal mucosa as a route for systemic drug delivery. J Pharm Pharm Sci 1998;1:15-30.

4. Sravanthi RR, Rajalakshmi R, Krishna MSB, Rupangada V, Ramya SE. A review on Mucoadhesive buccal films. Int J PharmTech Res 2014;6:1665-78.

5. James MR., Lionel DL, Timothy GK M, Albert F. 5th ed. A textbook of clinical pharmacology and therapeutics; 1999. p. 187-8.

6. Jones, Bartlett. Nurse's drug handbook. Tenth ed; 2011. p. 173-4.

7. Swectman SS. Martindale: the complete drug reference. 36th ed. Pharmaceutical Press: London; 2009. p. 1239.

8. Jackson JV, Moss MS, Widdp B. Clark's Isolation and Identification of drugs. Second ed. pharmaceutical Press: London; 1986. p. 426.

9. Panigrahi L, Pattnaik S, Chosal S. Design and characterization of mucoadhesive buccal patches of salbutamol sulphate. Acta Pol Drug Res 2004;61:350-60.

10. Naffe NA, Roralie NA, Ismail FA, Mortada LM. Design and formulation of mucoadhesive buccal patches containg cetylpyridium chloride. Acta Pharm 2003;53:199-212.

11. Bansal S, Bansal M, Gavg G. Formulation and evaluation of fast dissolving film of an antihypertensive drug. Int J Pharm Chem Biol Sci 2013;3:1097-108.

12. Rasool BK, Khan SA. In vitro evaluation of miconazole mucoadhesive buccal film. Int J Appl Pharm 2010;2:23-6.

13. Manubolu K, Chandana AV, Prakash P, Sujatha B, Rani SV, Radhika KV. Formulation and in vitro characterization of amitriptyline buccal films. World J Pharm Pharm Sci 2014;3:1547-55.

14. Velmurugan S, Srinivas P. Formulation and in vitro evaluation of losartan potassium mucoadhesive buccal tablets. Asian J Pharm Clin Res 2013;2:125-30.

15. Kshirasagar N, Thamada N, Naik BK, Gopal MS. Design and evaluation of chitosan containing a mucoadhesive buccal patch of fluoxetine HCl. Int J Sci Public 2012;2:1-5.

16. Nagendrakumar D, KeshavshettiG G, Mogule P, Swamti S, Swami H. Formulation and evaluation of fast dissolving oral films of metoprolol succinate. Int J Eng Appl Sci 2015;6:28-38.

17. Viswanadhan PV, Padole A, Abraham A, Mathew ST. Buccal tablets of lisinopril by direct compression method for buccal drug delivery. Int Res J Pharma 2012;2:30-8.

18. Jagdale SC, Mohanty P, Aniruddha R, Chabukswar AR, Kuchekar BS. Development of buccal patches for delivery of darifenacin from beta-cyclodextrin complexes. J Basic Appl Pharm Sci 2014;35:29-39.

19. Saritha T, Balaji A. Design and evaluation of forskolin buccal mucoadhesive microspheres. Int J Cur Pharm Res 2015;7:17-21.

20. Muthukumaran M, Dhachinamoorthi D2, Chandra SKB. Development and Optimisation of hydralazine $\mathrm{HCl}$ sustained released mucoadhesive buccal tablets using 23 factorial design. Int J Adv Pharm Gen Res 2013;1:20-32.

21. Raju KU, Kumar A, Deepika B, Eswaraiah MC, Rao AS. Formulation and in vitro evaluation of buccal tablets of captopril. Int Res J Pharm Appl Sci 2012;2:21-43. 
22. Parmar VJ, Lumbhani AN, Vijayalakshmi P, Sajal J. Formulation development and evaluation of buccal films of carvedilol. Int J Pharm Sci Res 2010;1:149-56.

23. Patil DA, Patil GB, Deshmukh PK, Belgamwar VS, Fursule RA. Chitosan-coated mucoadhesive multi particulate drug delivery system for gliclazide. Asian J Pharm Clin Res 2009;2:62-8.

24. Kuma BV, Kumar AA, Sudheer B, Kumar SK, Srinirasa RV, Kirtindhi $\mathrm{K}$, et al. Formulation design, invitro evaluation and stability studies on mucoadhesive buccal Films of antianginal calcium channel. J Appl Pharm Sci 2011;1:136-42.

25. Chambi HNM, Grosso CRT. Mechanical and water vapor permeability, properties of biodegradable films based on methylcellulose, glucomannan, pectin and gelatin. Cienc Tecnol Ali Comp 2011;31:739-46.

26. Sobral PJA, Menegalli FC, Hubinger MD, Roques MA. Mechanical, water vapor barrier and thermal properties of gelatin based edible film. Food Hydrocolliods 2001;15:423-32.

27. Abu-Huwaij R, Assaf S, Salem M, Sallam A. Mucoadhesive dosage form of lidocaine hydrochloride: mucoadhesive and physicochemical characterization. Drug Dev Ind Pharm 2007;33:855-64.

28. David SRN, Rajabalaya R, Aand Zhia ES. Development and in vitro evaluation of the self-adhesive matrix-type transdermal delivery system of ondansetron hydrochloride. Trop J Pharm Res 2015;14:211-8.

29. Vishnu YV, Chandrasekhar K, Ramesh G. Development of mucoadhesive patches for buccal administration of carvedilol. Curr Drug Delivery 2007;4:27-39.
30. Puratchikody A, PrasanthVV, Mathew ST, Kumar BA. Mucoadhesive patch of salbutamol sulphate for unidirectional buccal drug delivery: development and evaluation. J Cur Drug Delivery 2011;8:416-25.

31. Mohamed MI, Afify EA, Mekhel MKG. Formulation and evaluation of antiasthmatic drug montelukast in the mucoadhesive buccal patch. J Coast Life Med 2014;2:907-14.

32. Yousif NZ, Mariae KN. Optimization and evaluation of metoclopramide $\mathrm{HCl}$ as a mucoadhesive buccal patch. World J Pharm Res 2015;4:79-99.

33. Deore VA, Kumar RS, Gide PS. Development and statistical optimisation of mucoadhesive buccal patches of indomethacin: in vitro and ex vivo evaluation. Int Int J Adv Pharm Biol Chem 2013;2:405-22.

34. El-shabouri MH, Abdel-Aleen HM, Soliman OM, Eldahhan MS. Formulation and evaluation of buccoadhesive captopril tablet. Bull Pharm Sci 2009;32:45-64.

35. Thadkala K, Kumari NPP, Prathyush R, Raju A. Formulation, development, optimization and characterization of floating beads of captopril. Int J Pharm Res All Sci 2013;2:32-46.

36. Sunitha HS, Parthiban S, Vikneshwiri A, Seuthil KGP, Tamiz MT. Development and evaluation of Captopril fast dissolving a tablet by complexation techniques using guar gum as a super disintegrant. Int J Res Pharm Nanosci 2015;4:72-84.

\section{How to cite this article}

- Zainab Ahmed Sadeq, Nawal Ayash Rajab. Studying the effect of different variables on the formulation of mucoadhesive buccal patches of captopril. Int J Appl Pharm 2017;9(2):16-21. 